\title{
EDUCAÇÃO PARA PRÓ-SOCIABILIDADE: UMA LIÇÃO DE CIDADANIA?
}

\author{
Sílvia H. Koller (*)
}

\section{RESUMO}

$O$ objetivo deste artigo é discutir algumas questões conceituais sobre pró-sociabilidade e suas aplicaçōes para a Educação. Alguns teóricos da Psicologia concordam que a pró-sociabilidade revela aspectos psicológicos positivos e sadios da personalidade dos indivíduos, e tem sido considerada como a base de uma vida civilizada. Pode manifestar-se no contexto social, sendo garantida e intensificada, por meio de programas de educação pró-social que promovam o desenvolvimento humano $e$ cidadania.

O objetivo deste artigo é discutir questões conceituais sobre pró-sociabilidade e suas aplicações para a Educação. Os teóricos da Psicologia concordam que a pró-sociabilidade revela aspectos psicológicos positivos e sadios da personalidade dos indivíduos. Hoffman (1984) afirma que a pró-sociabilidade e a empatia, que dela deriva, são as bases de uma vida civilizada. Pró-sociabilidade é definida por Eisenberg $(1982,1992)$ como ações e/ou julgamentos voluntários que visem consequências positivas, tendo como motivação básica beneficiar o outro, sem influências ou pressões externas. O comportamento de ajuda deve ocorrer sem expectativas de prêmios ou recompensas materiais ou sociais para o benfeitor. A pró-sociabilidade pode manifestar-se por meio de intenções, ações, pensamentos ou palavras expressas por uma pessoa diante de um dilema moral (Eisenberg, 1982, 1992). Manifesta-se no contexto social, podendo ser garantida e intensificada por programas de educação pró-social que promovam o desenvolvimento humano.

O desenvolvimento moral pró-social está relacionado ao processo de aquisição e mudança dos julgamentos e comportamentos de ajuda ou benefício dirigidos a outros indivíduos ou grupos e atos de civilidade (Eisenberg \& Mussen, 1989; Oliner, 1985/1986). Atitudes ou intenções de compartilhar e ajudar apa-

* Correspondência: Sílvia H. Koller, CPG Psicologia/UFRGS, Rua Ramiro Barcelos, 2600/ 104, 90035.003 - Porto Alegre, RS. E-mail: KOLLERSH@ VORTEX.UFRGS.BR. Fone: (051) 3309507, Fax: (051) 3304797.

Paidéia FFCLRP-USP, Rib.Preto, fev/ago 97. 
recem e se modificam no decorrer da vida das pessoas, em função da presença e da interação de fatores do desenvolvimento humano, tais como idade, características de personalidade, motivações, habilidades, educação e condições situacionais. Psicólogos e pesquisadores têm tentado criar modelos teóricos explicativos do desenvolvimento do julgamento moral pró-social e dos comportamentos de ajuda e suas formas de aplicação (Eisenberg, 1986; Koller \& Bernardes, 1997).

Uma das aplicações pode ser proposta como um programa de Educação para a Pró-sociabilidade. É possível que ao se expor pessoas a modelos ou a experiências de ajudar aos outros, estas desenvolvam ações pró-sociais com maior probabilidade (Radke-Yarrow, Zahn-Waxler, \& Chapman, 1983). Um programa de educação para a pró-sociabilidade pode ser entendido como Educação para a Cidadania, uma vez que os comportamentos pró-sociais servem para integrar as pessoas em suas comunidades, como membros que compartilham responsabilidades pessoais, voluntárias e dirigidas aos outros. Os valores dominantes e a educação moral pró-social enfatizam o processo de desenvolvimento humano, bem como o produto, isto é, a pessoa deve desenvolver comportamentos de ajuda efetivos sem expectativas de recompensa, pelo simples fato de melhorar a qualidade de vida do outro e fazer uma sociedade melhor. Para Suchodolski (1979), a educação moral converte-se, gradativamente, em um problema de caráter social amplo, não se limitando ao indivíduo e às suas relações mais próximas.

Haste (1993) aprofunda esta discussão, enfatizando que a cidadania está diretamente relacionada com a criatividade moral, a qual define em termos de visão, eficácia e responsabilidade. Criatividade moral é uma capacidade da pessoa que transforma seus atos morais em ações comuns e espontâneas, carregadas de extraordinária responsabilidade moral. Este exercício criativo de cidadania implica em atitudes, que se expressam tanto no domínio público quanto no privado.

Para Castillejo Brull (1984), a pessoa constrói-se ou configura-se, dependendo de sua potencialidade educável e do processo de interrelação com o meio. $\mathrm{O}$ processo e o produto desta configuração humana será distinta em cada caso, atendendo ao vetor de intervenção educativa e à singularidade de cada um. Sureda Negre (1987) enfatiza, no entanto que, embora a educação reflita-se no ambiente, por meio da atuação da pessoa e de sua ação nos grupos ou nas comunidades sociais, o primeiro ambiente a ser privilegiado deve ser $o$ Eu. No entanto, este Eu necessita de uma consciência abrangente que contemple o social, desafiando as condições de injustiça e ignorância que afligem a Humanidade. 
A função prioritária da pessoa visará, então, intervir para modificar situações sociais por meio de estratégias de Educação para a Cidadania. A sociedade poderá ser muito mais justa e sábia, quando as pessoas nas suas comunidades, culturas e sociedades puderem decidir, dignamente, suas vidas, suas experiências, seu trabalho, sua ação política e seu espaço social (Mosquera, 1990).

Embora a definição de cidadania tenha variado em diferentes tempos e lugares, ela tem sido amplamente relacionada com os conceitos legais concedidos pela sociedade aos direitos e os deveres de cada pessoa integrante de uma nação e de uma comunidade. A Educação para a Cidadania objetiva esclarecer as pessoas e solidificar seus limites legais como cidadãos de uma nacionalidade e como participantes de um grupo social comunitário. Enquanto cidadãos compartilham relações impessoais e legais dentro de uma nação, membros de uma comunidade têm vínculos pessoais e voluntários uns com os outros. Os comportamentos e julgamentos pró-sociais têm um papel vital dentro do contexto comunitário, propiciando o desenvolvimento de um senso de pertinência e participação, que McMillan (1996) denomina como senso de comunidade. Hill (1996) concorda com estas posições, acrescentando que o senso de comunidade psicológica implica em uma forma de apego (attachment), ou seja, interações frequentes sensitivas e responsivas, não apenas com um, mas com muitos e diferentes membros da comunidade. McMillan e Chavis (1986) apontam para quatro elementos do senso de comunidade: afiliação, influência, integração e preenchimento de necessidades. As pessoas em uma comunidade estão engajadas em compartilhar e trocar atos de civilidade, ajuda e gentileza, que melhoram a qualidade de suas vidas e intensificam seus sentimentos de responsabilidade com relação aos outros. Nestes casos, a pró-sociabilidade pode ser ensinada através de experiências planejadas, que envolvam efetivamente situações de ajuda. A educação pró-social deve ser dirigida a alvos pré-determinados e intencionais. Todavia, apenas promover intenções de ajuda não assegura consequências efetivas, por isto devem ser planejadas e refletidas as ações de intervenção.

A educação com objetivos pró-sociais pode ser implementada nos mais variados segmentos das relações humanas, como a escola, as instituições e a rua. Na escola, por exemplo, a implementação dos objetivos pró-sociais não requer a reestruturação radical do currículo escolar, mas a alteração da direção e da ênfase deste currículo. Os valores pró-sociais podem ser aprendidos, por exemplo, através de tarefas e materiais de ensino que promovam preocupação pelos outros. As habilidades educacionais básicas e os processos intelectuais complexos podem ser direcionados, em parte, para propostas pró-sociais. Uma 
parte do currículo escolar em áreas como Ciências, Matemática ou Estudos Sociais precisa questionar-se sobre como aplicar estes conhecimentos para que sejam úteis aos seus estudantes e como podem ser aproveitados socialmente, na comunidade em que eles vivem.

Esta preocupação tem estado presente na literatura sobre educação para a moralidade (Raths, Harmin, \& Simon, 1966; Coombs \& Meux, 1971; Kohlberg, 1967,1975 , entre outros). Técnicas educacionais foram propostas para promover o desenvolvimento de valores. Raths, Harmin e Simon (1966) criaram uma técnica de clarificação de valores, sugerindo sua inserção nos currículos escolares. Esta técnica implicava na transmissão de valores pelos professores, a partir da apresentação dos próprios valores aos seus estudantes. Outra técnica chamada análise de valores ou abordagem para decisão cognitiva, foi proposta por Coombs e Meux, em 1971. O objetivo da análise de valores era auxiliar os estudantes a adquirir a capacidade e a disposição para decidir e agir racionalmente (Oliner, 1985/1986).

As técnicas de clarificação e de análise de valores mantiveram-se apenas como estratégias de ensino, mas seu impacto teórico e prático foi limitado. A abordagem teórica de Kohlberg $(1967,1975)$ sobre a moralidade alcançou, no entanto, uma profunda repercussão em várias disciplinas. Kohlberg propôs a Comunidade Justa como modelo de programa para a educação moral (Power, Higgins, \& Kohlberg, 1989). Baseado em sua teoria de desenvolvimento moral, propôs a aplicação na educação com o objetivo de promover o desenvolvimento dos indivíduos desde os estágios mais primitivos do raciocínio moral até os estágios mais elaborados (Biaggio, 1997). A estratégia consistia em fazer com que os estudantes se deparassem com uma situação conflitiva entre dois princípios morais. O estudante deveria, então, fazer uma escolha, sendo o papel do professor apenas de facilitador.

A educação pró-social não foi, necessariamente, excluída ou incluída em alguma destas abordagens citadas anteriormente. Todavia, sua importância deve ser considerada como primordial para os educadores. A educação pró-social deve ser implementada através de um clima que permita e favoreça o cultivo de comportamentos e julgamentos, legitimando a pró-sociabilidade como um processo de Educação para a Cidadania e promovendo o sentido de comunidade entre os participantes.

O ponto mais crítico da educação pró-social consiste em conduzir a prática educacional em direção à aquisição de vínculos que aumentem o senso de comunidade e o sentimento de responsabilidade entre seus integrantes, ao invés de meras recompensas externas ou internas aos atos pró-sociais. As práticas educacionais atuais, em geral, direcionam o comportamento dos estudantes 
para seus próprios interesses, como se observa nas competições, premiações por melhores notas e atitudes. Na promoção do sentido de comunidade, comportamentos pró-sociais podem ser obtidos pela argumentação de que todos os integrantes daquela comunidade são interdependentes e que apenas mediante a cooperação, a colaboração, a troca e a reciprocidade, pode ser garantida uma qualidade de vida melhor a todos.

Muitas pessoas, no entanto, falham em suas respostas a esses apelos. Nem a atração pelo sucesso grupal, nem a reciprocidade são suficientes para motivar a alguns a modificarem seus comportamentos ou a se sensibilizarem para a pró-sociabilidade, mantendo-se alienados destas manifestações na escola e na sociedade. Talvez ajam assim porque se sintam incompetentes e apresentem baixa auto-estima, convencidos que ser pró-social está fora do seu alcance. Algumas vezes, até mesmo as escolas, as instituições e a sociedade rotulam os indivíduos como "perdedores" ou como aqueles que têm pouco a oferecer. A menos que outros afortunados ajam em seu favor, experimentam dificuldades e isolamento social, que podem até mesmo ser expressos por atos hostis e anti-sociais. Uma forma de garantir a inclusão pertinente no contexto social pode se dar pelo encorajamento dos outros (mais pró-socialmente competentes) a auxiliá-los. Esta ética de ajuda baseada nas necessidades dos outros enfatiza a valorização das pessoas como seres humanos.

Não é função primordial da nossa sociedade produzir seres pró-sociais, ou seja, benfeitores que estão preparados a agir em favor dos outros a um custo extremo para si próprios. A competição, a reciprocidade e o contrato continuarão, no entanto, a ser meios essenciais de organização das relações interpessoais e sociais. Contudo, uma sociedade integrada por membros responsáveis de uma comunidade não existirá, a menos que alguns comportamentos, intenções e valores sejam pró-sociais. As atividades nas escolas e em outras instituições que trabalhem com crianças e adolescentes devem ser, deliberadamente, planejadas para motivar e promover intenções e valores de ajuda, para que o futuro possa antever um novo padrão de relações e a função de nossa sociedade seja baseada em civilidade. Para responder com competência e sentir satisfação interna através da ajuda ao outro, o indivíduo necessita de oportunidades para participar efetivamente, em comportamentos pró-sociais, refinando, assim, suas habilidades em ajudar.

A expressão de comportamentos e julgamentos pró-sociais depende da situação com a qual os indivíduos se deparam. Por isso mesmo os mais intensos esforços de transmitir valores e virtudes podem ser ineficazes. Crianças podem se perceber como benfeitores potenciais experimentando mais conforto moral para si próprios e para os outros envolvidos. Igualdade, respeito pelas 
pessoas e seus patrimônios, tolerância e sensibilidade são aspectos facilmente transmissíveis racionalmente, mas muitas vezes, completamente relegados diante de condições especiais do cotidiano na nossa sociedade.

Os objetivos da Educação Pró-social devem incluir o desenvolvimento das intenções e valores pró-sociais e da capacidade de agir pró-socialmente, bem como a promoção de processos intelectuais, envolvendo tomada de decisão e participação dos indivíduos em situações pró-sociais efetivas e reais no cotidiano. Comportamentos de ajuda tendem a ser resultantes da internalização de valores. O despertar para intenções pró-sociais, frequentemente, ocorre como resultado de sentimentos associados à empatia e à compaixão (Feshbach, 1982; Hoffmann, 1982; Krebs, 1975). Compartilhar emoções e experiências com os outros encorajam respostas empáticas. Por isto, as aulas de Literatura, de Teatro, de Música e de outras Artes são veículos que podem ser utilizados para sensibilizar estudantes a questionar as injustiças, as desigualdades e as necessidades dos outros. Da mesma forma, as aulas de História Antiga e Contemporânea, através da discussão de episódios variados, podem concorrer para o desenvolvimento de posições empáticas com relação a personagens, ídolos e outros povos. As aulas de Educação Religiosa podem ser aplicadas em ações na comunidade, em direção a potenciais receptores de ajuda, nas quais o estudante possa compartilhar pessoalmente da experiência de receber e prestar ajuda. Mais do que a entrega de um donativo, que pode ser de baixo custo para alguns estudantes, compartilhar o momento da entrega pode gerar sentimentos pró-sociais mais efetivos. O auge de satisfação pró-social pode se dar, quando o indivíduo coloca-se no lugar do outro e expõe-se à experiência de perceber o contentamento daquele que recebe.

A escola, como as demais instituições podem apresentar condições para realização deste programa de educação, salientando seus objetivos por meio de instruções diretas e da atribuição de responsabilidade. Cabe a elas, eliciarem e manterem o comportamento pró-social da criança, sem que tenham caráter autoritário (Moore \& Eisenberg, 1984). A importância de algumas práticas pedagógicas foram testadas e demonstraram aumento da ocorrência de comportamentos pró-sociais em atividades expressivas e acadêmicas, incrementando o comportamento pró-social (Branco \& Mettel, 1984; DelPrette, Branco, Ceneviva, Almeida, \& Ades, 1986). A prática de desempenho de papéis e a tomada da perspectiva do outro, proporcionadas pela educação, podem desenvolver atitudes pró-sociais (Carlo, Knight, Eisenberg, \& Rotenberg, 1991; Kohlberg, 1984, Krebs \& Sturrup, 1981). Práticas educacionais que estimulam a aquisição de experiências morais e sociais, também promovem o desenvolvimento. O próprio grupo de crianças ou adolescentes na escola, por meio da 
intervenção de um educador social, pode experimentar a possibilidade de compartilhar em suas tarefas rotineiras. $\mathrm{Na}$ escola, um colega pode ajudar o outro na sua tarefa, ensinar a utilizar um aparelho novo, indicar a localização de algumas salas a alunos novos no ambiente. Podem ainda, gerar situações tais como tutorar outros, organizar grupos de aconselhamento, de monitoramento da segurança e de moderadores de conflito. A comunicação efetiva entre os estudantes também é importante, principalmente quando associada à discussão sobre direitos e ética.

Essas atitudes são consistentes com outros objetivos educacionais, direcionados a propostas pró-sociais e salientam a atuação daqueles que promovem o bem-estar geral. Fazer isto não requer a abdicação ou eliminação de outras propostas educacionais, mas exige uma modificação na ênfase. O processo de desenvolvimento do julgamento moral pró-social deve enfatizar que a aprendizagem não seja valorizada apenas pelo ganho pessoal, mas pelo que pode fazer pelos outros. Em um nível intelectual mais complexo, a capacidade de agir pró-socialmente envolve habilidades de colocar-se no lugar do outro, propondo ações pró-sociais e avaliando o impacto de comportamentos de modelos relevantes. Este processo pode se dar através da discussão de problemas da escola, da comunidade, nacionais ou mundiais, tais como problemas ecológicos, manutenção de paz no mundo, tolerância entre os povos, entre outras questões sociais, políticas e históricas. A discussão dessas questões deve ser encaminhada para uma decisão pró-social e para a avaliação do bem-estar geral.

A educação pró-social sugerida acima não consiste apenas em um conjunto de tarefas, mas em um compromisso que deve ser assumido por todos aqueles que se consideram educadores sociais, no sentido de formar um país de cidadãos. A excessiva atenção ao desempenho e ao sucesso individual tem obscurecido uma das principais missões da escola, que é a de produzir pessoas capazes de viver com algum nível de cuidado e responsabilidade pelos outros e por seus próprios atos. A mensagem pela qual as escolas comunicam o bom rendimento escolar é importante, no entanto o sucesso significa, também, estabelecer um compromisso de valor com os outros.

A sociedade, no decorrer da história, tem exigido que a escola cumpra com sua função econômica e profissionalizadora (March I Cerdá, 1987). No entanto, é chegado o momento em que a sociedade tem que exigir uma posição da escola com relação à grave problemática social do mundo contemporâneo. A educação pró-social pode iniciar na escola e ser expandida, também, para vários grupos e instituições sociais. A família, os grupos comunitários, a igreja, entre outros, podem aproveitar suas reuniões para alcançar os objetivos desta forma de educação. Mosquera (1985) define outras formas de educação que 
preenchem as lacunas da Educação Formal, como por exemplo, a Educação Informal e a Educação Não-formal. A Educação Informal pode ser uma das soluções alternativas na conquista de novos conhecimentos, como também de atitudes, valores, aptidões, experiência cotidiana e influências do meio ambiente. Pela Educação Não-formal adquire-se conhecimento por meio de toda atividade educacional organizada que esteja fora do sistema de ensino formal.

A existência de um ambiente reforçador nos quais as relações entre os educadores e as crianças sejam significativas pode gerar relações de confiança e de mútua ajuda. A partir destas relações, os educadores podem propiciar comportamentos pró-sociais e desencorajar comportamentos anti-sociais. $\mathrm{Na}$ sociedade, a utilização de animação sócio-cultural talvez seja a estratégia mais eficaz (Caride Gomez, 1986). Animação sócio-cultural consiste em ações que "dirigidas à elaboração e desenvolvimento de um projeto, essencialmente prático, de conscientização, participação e integração sócio-cultural dos indivíduos, dos grupos elou instituições" na comunidade, promovem as transformações e as mudanças requeridas por uma qualidade de vida ajustada à construção crítica da realidade (Caride Gomez, 1986, p. 132). Entre as várias metas a que se propõe, a animação sócio-cultural visa a libertação do homem e sua participação numa democracia, pela inovação e transformação social, assumindo uma identidade cultural e desenvolvimento social (Monera Olmos, 1987).

$O$ educador representa um agente no desenvolvimento do senso de comunidade psicológica, enfatizando o pertencimento e proporcionando práticas disciplinares e de atitudes que levam o aluno a entender as convenções sociais e culturais de seu grupo. Colabora desenvolvendo os sentidos à solidariedade, à responsabilidade e à convivência. Sua atuação, centrada na afetividade e na formação de vínculo, pode ser sinônimo de esperança por uma sociedade melhor. A educação auxilia na superação pessoal, na interpretação da própria existência como parte de um todo, que tem capacidade para construir uma nova realidade. O educador é um ponto de referência e de identificação entre a criança e a comunidade. Sua intervenção educativa pode alcançar objetivos psicológicos fundamentais como o reestabelecimento do equilíbrio pessoal, a inibição de condutas agressivas, o colocar-se no lugar do outro e a retomada da iniciativa. Estes objetivos psicológicos cumpridos resultarão na maior integração da personalidade e na auto-percep̧̧ão como um ser pró-social.

Estas práticas permitirão à criança a se perceber como pertinente a um grupo. Os educadores podem ensinar habilidades para facilitar, também, $o$ acesso legal a benefícios. Este seria talvez um passo a frente na sua busca da cidadania, uma vez que ser cidadão é cumprir com seus deveres e desfrutar de seus direitos. Talvez seja importante, antes de finalizar, discutir como se pode edu- 
car pessoas para desfrutarem de seus direitos? Haste (1993) enfatiza que para tal, é necessário, primeiramente que a pessoa conheça os seus direitos, ou seja tenha visão de suas possibilidades, capacitando-se no sentido de alcançá-los. Desta forma, constróe-se sua eficácia: A pessoa deve aprender a clamar por seus direitos de forma competente e crítica, respeitando os direitos dos outros. A conquista de seus objetivos, pode implicar na busca de novos direitos, contestando sistemas opressivos e limitantes. Este ponto exige maior competência da pessoa, no sentido de discernir bem seus próprios limites e possibilidades. A Educação para a Cidadania cria tensão entre a conformidade aos papéis e o confrontamento com o estabelecido, na busca de mudanças. As pessoas devem ser capazes de questionar o sistema de valores que lhes é dado, compreender os princípios que regem a sua sociedade e não ter tantas certezas, mas o pensamento em constante desafio, vendo além das limitações convencionais. Para ser eficaz, no entanto, é necessário que associe suas idéias a ações responsáveis, enfatizando a ordem e a responsabilidade, colaborando para manter as leis, evitando o conformismo.

Educar para a pró-sociabilidade e para a cidadania implica em tirar o véu das dúvidas e relutâncias e ajustar as lentes dos indivíduos, para o compromisso e responsabilidade que obrigam os deveres e o conhecimento de direitos de si mesmo e dos outros.

Esta proposta pode ser muito otimista e mesmo muito ambiciosa, mas como confirmaremos estas opiniões se não tentarmos executá-la?

\section{REFERÊNCIAS BIBLIOGRÁFICAS}

Biaggio, A. M. B. (1997). Kohlberg e a 'Comunidade Justa': Promovendo o senso ético e a cidadania na escola. Psicologia Reflexão e Crítica, 10, 17 46.

Branco, A., \& Mettel, T. (1984). Comportamento pró-social: Um estudo com pré-escolares. Psicologia, 10, 43-61.

Campos, M. M. M. (1985). Escola e participação popular. Em F. R. Madeira \& G. N. Mello (Orgs.), Educação na América Latina. São Paulo: Cortez.

Caride Gomez, J. A. (1986). Educación y animación sociocultural: La pedagogia social como modelo de intervención. Madri: Narcea. 
Carlo, G., Knight, G., Eisenberg, N., \& Rotenberg, K. (1991). Cognitive processes and prosocial behaviors among children the role of affective attributions and reconciliations. Developmental Psychology, 27, 456-461.

Castillejo Brull, J. L. (1984). El concepto de educacion desde una perspectiva intervencionista (primeras aproximaciones). Em P. Aznar \& J. L. Castillejo Brull (Eds.) Conceptos y propuestas. Valencia: EDITA.

Colom Canellas, A. J. (1987). Area de la recuperacion y reinsercion social: El educador de calle. Em A. J. Colom (Ed.), Modelos de intervención socioeducativa. Madrid: Narcea.

Coombs, J. R. \& Meux, M. (1971). Teaching strategies for value analysis. Em L. E. Metcalf (Ed.) Values Education: Rationale, Strategies, and Procedures (41 Yearbook). Washington: National Council for the Social Studies.

DelPrette, A., Branco, A., Ceneviva, M., Almeida, N., \& Ades, C. (1986). A utilização do objeto nas interações pró-sociais apresentadas por crianças da pré-escola. Psicologia Teoria e Pesquisa, 2, 245-264.

Eisenberg, N. (1982). The Development of Prosocial Behavior. New York: Academic Press.

Eisenberg, N. (1986). Altruistic Emotion, Cognition, and Behavior. Hillsdale, NJ: Lawrence Erlbaum Associates.

Eisenberg, N. (1992). The Caring Child. Cambridge: Harvard University Press.

Eisenberg, N. \& Mussen, P. (1989). The roots of prosocial behavior in children. Cambridge: Cambridge University Press.

Feshbach, N. D. (1982). Sex differences in empathy and social behavior in children. In: N. Eisenberg (Ed.). The Development of Prosocial Behavior (p.315-358). New York: Academic Press.

Haste, H. (1993). Moral creativity and education for citizenship. Creativity Research Journal, 6, 153-164.

Hill, J. L. (1996). Psychological sense of community: Suggestions for future research. Journal of Community Psychology 24, 431-438.

Hoffman, M. L. (1982). Development of prosocial motivation: Empathy and guilt. Em N. Eisenberg (Ed.), The development of Prosocial Behavior (p.281313). New York: Academic Press.

Hoffman, M. L. (1984). Empathy, its limitations, and its role in a comprehensive moral theory. Em W. M. Kurtines \& J. L. Gewirtz (Eds.), 
Morality, moral behavior, and moral development (p.283-302). New York: Wiley.

Kohlberg, L. (1967). Moral and religious education and the public schools: A development view. Em T. Sizer (Ed.), Religion and Public Education. Boston: Houghton Mifflin.

Kohlberg, L. (1975). Moral education for a society in moral transition. Educational Leadership, 33, 46-54.

Kohlberg, L. (1984). Essays on moral development: The psychology of moral development (Vol. II). New York: Harper \& Row.

Koller, S., \& Bernardes, N. (1997). Desenvolvimento moral pró-social: Similaridades e diferenças nos modelos teóricos de Kohlberg e Eisenberg. Estudos de Psicologia, 2.

Krebs, D. (1975). Empathy and altruism. Journal of Personality and Social Psychology, 32, 1134-1146.

Krebs, D. \& Sturrup, B. (1981). Role-taking ability and altruistic behavior in elementary school children. Journal of Moral Education, 11, 94-100.

March I Cerdá, M. X. (1987). La profesionalizacion del papel pedagogico de las empresas. Em A. J. Colom (Ed.), Modelos de intervención socioeducativa. Madrid: Narcea.

McMillan, D. W. (1996). Sense of Community. Journal of Community Psychology, 24, 315-325.

McMillan, D. W. \& Chavis, D. (1986). Sense of Community: A definition and theory. Journal of Community Psychology, 14, 6-23.

Moneras Olmos, M. L. (1987). La animacion sociocultural como un nuevo tipo de educacion. Em A. J. Colom (Ed.), Modelos de intervención socioeducativa. Madrid: Narcea.

Moore, B., \& Eisenberg, N. (1984). The development of altruism. Em G. J. Whitehurst (Ed.), Annals of Child Development (Vol. 1, pp. 107-174). Greenwich: JAI Press.

Mosquera, J. J. M. (1985). Análise crítica da educação de adultos através de características psicossociais do seu desenvolvimento. Educação, 9, 1732.

Mosquera, J. J. M. (1990). A universidade e a produção do conhecimento. Logos, $2,6-10$.

Oliner, P. M. (1985/1986). Legitimating and implementing prosocial education. Humboldt Journal of Social Relations, 13, 391-410. 
Power, C., Higgins, A., \& Kohlberg, L. (1989). Kohlberg's approach to moral education. Cambridge: Harvard University Press.

Radke-Yarrow, M., Zahn-Waxler, C., \& Chapman, M. (1983). Children's prosocial dispositions and behavior. Em H. Mussen (Ed.), Handbook of Child Psychology. Socialization. Personality and Social Development, (Vol.4, pp. 469545). New York: Wiley.

Raths, L., Harmin, M., \& Simon, S. B. (1966). Values and teaching: Working with values in the classroom. Columbus: Charles E. Merrill.

Suchodolski, B. (1979). Tratado de Pedagogia. Barcelona: Ediciones Peninsula.

Sureda Negre, J. (1987). Programas socioeducativos de educacion ambiental no formal. Em A. J. Colom (Ed.), Modelos de intervención socioeducativa. Madrid: Narcea.

\section{ABSTRACT}

This paper aims to discuss some conceptual issues of prosociability and its aplications to Education. Some theorists, in Psychology, agreed that prosociability reveals some health and positive psychological aspects and it has been considered as the bottom of a civilized life. It can be seem in the social context as prosocial educational programs, that foster human development and citizenship.

Key-words: prosocial, moral, citizenship, education

Palavras-chave: pró-social, moral, cidadania, educação 